\title{
Cost effectiveness of strategies to combat cardiovascular disease, diabetes, and tobacco use in sub-Saharan Africa and South East Asia: mathematical modelling study
}

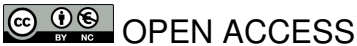

\author{
Mónica Ortegón researcher ${ }^{1}$, Stephen Lim associate professor of global health ${ }^{2}$, Dan Chisholm \\ health economist ${ }^{3}$, Shanthi Mendis coordinator ${ }^{4}$
}

${ }^{1}$ School of Medicine and Health Sciences, Universidad del Rosario, Bogotá, Colombia; ${ }^{2}$ Institute for Health Metrics and Evaluation, University of Washington, Seattle, USA; ${ }^{3}$ Department of Health Systems Financing, World Health Organization, Geneva, Switzerland; ${ }^{4}$ Department of Chronic Diseases and Health Promotion, World Health Organization, Geneva

\begin{abstract}
Objective To determine the relative costs and health effects of interventions to combat cardiovascular disease, diabetes, and tobacco related disease in order to guide the allocation of resources in developing countries.

Design Cost effectiveness analysis of 123 single or combined prevention and treatment strategies for cardiovascular disease, diabetes, and smoking by means of a lifetime population model.

Setting Two World Health Organization sub-regions of the world: countries in sub-Saharan Africa with very high adult and high child mortality (AfrE) and countries in South East Asia with high adult and high child mortality (SearD).
\end{abstract}

Data sources Demographic and epidemiological data were taken from the WHO databases of mortality and global burden of disease. Estimates of intervention coverage, effectiveness, and resource needs were drawn from clinical trials, observational studies, and treatment guidelines. Unit costs were taken from the WHO-CHOICE (Choosing Interventions that are Cost-Effective) price database.

Main outcome measures Cost per disability adjusted life year (DALY) averted, expressed in international dollars (\$Int) for the year 2005.

Results Most of the interventions studied were considered highly cost effective, meaning they generate one healthy year of life at a cost of $<\$$ Int2000 (which is the gross domestic product per capita of the two regions considered here). Interventions that offer particularly good monetary value, and which could be considered for prioritised implementation or scale up, include demand reduction strategies of the Framework Convention for Tobacco Control $(<\$$ Int950 and $<\$$ Int200 per DALY averted in AfrE and SearD respectively); combination drug therapy for people with a $>25 \%$ chance of experiencing a cardiovascular event over the next decade, either alone or together with specific multidrug regimens for the secondary prevention of post-acute ischaemic heart disease and stroke $(<\$ \operatorname{lnt150}$ and $<\$$ Int230 per DALY averted in AfrE and SearD respectively); and retinopathy screening and glycaemic control for patients with diabetes $(<\$$ Int2100 and $<\$$ Int950 per DALY averted in AfrE and SearD respectively).

Conclusion This comparative economic assessment has identified a set of population-wide and individual strategies for prevention and control of cardiovascular disease that are inexpensive and cost effective in low resource settings.

\section{Introduction}

There is growing concern about the escalating burden of non-communicable diseases and injuries throughout the world, from both epidemiological and economic perspectives. Lives lost to diseases such as cancer, cardiovascular disease, and diabetes-together with the often longstanding disability associated with them - have an economic impact on households and communities, both through the uptake of health services and goods that diverts expenditure away from other possible

Correspondence to: M Ortegón Carrera 24 \# 63C-69 Bogotá, Colombia monica.ortegon@urosario.edu.co

Extra material supplied by the author (see http://www.bmj.com/content/344/bmj.e607?tab=related\#webextra)

General appendix (referred to by all the papers in this cluster)

Appendices 1-5: Details of (1) countries in the epidemiological sub-regions, (2) effectiveness of tobacco control interventions, (3) effectiveness of cardiovascular disease interventions, (4) impact and costs of diabetes interventions, (5) resource use at patient level for cardiovascular disease interventions

Appendices 6 and 7: (6) Full results of costs, effects, and cost effectiveness of interventions, (7) cost per treated case for cardiovascular disease interventions 
uses and through loss of income or labour productivity. ${ }^{12}$ Despite these adverse consequences on health and economic welfare, non-communicable diseases and injuries have been neglected in international health and development initiatives. The recent high level meeting on non-communicable diseases at a special session of the United Nations General Assembly and the subsequent political declaration ${ }^{3}$ provides a political mandate and an unprecedented opportunity to develop an international policy framework for the prevention and control of non-communicable diseases. A key action in support of this strategy is the evidence on the interventions that work best at the lowest cost in the prevention and control of non-communicable disease and injuries, in developing regions with a high disease burden.

In this series of articles we examine the relative cost effectiveness of a comprehensive set of interventions and strategies for combating major non-communicable diseases and injury in economically developing regions of the world: this paper covers cardiovascular disease and some of its key risk factors (including raised blood pressure, raised blood cholesterol, and tobacco use), and the others assess respiratory disease (asthma and chronic obstructive pulmonary disease), cancer (of the breast, cervix, and colon or rectum), neuropsychiatric disorders (schizophrenia, bipolar affective disorder, depression, harmful alcohol use, and epilepsy), sense organ diseases (including cataract, trachoma, refractive error, and hearing loss), and road traffic injury. ${ }^{4-8}$ Although this list leaves some gaps in the diseases covered-musculoskeletal diseases and blood disorders, for example - these analyses provide the largest available database of comparable cost effectiveness estimates, which a final paper uses to identify key priorities for the prevention and control of non-communicable diseases and injuries. ${ }^{9}$ We also provide a companion paper that shows the use of these methods at the country level (Mexico), as opposed to the level of epidemiologically defined World Health Organization sub-regions. ${ }^{10}$

Cardiovascular disease is the single largest cause of mortality worldwide, accounting for 17 million deaths, equivalent to $29 \%$ of all deaths annually. We cover primary prevention efforts at both the population level (such as tobacco control measures, reduced dietary salt intake) and at the individual level (such as control of hypertension or blood cholesterol with drugs and combination drug therapy for individuals at high risk of a cardiovascular event) as well as secondary and tertiary prevention or management of ischaemic heart disease and stroke. We also include the management (but not prevention) of another major cardiovascular risk factor, namely diabetes and its associated complications (which account for more than another million deaths worldwide each year). Intervention cost effectiveness results for two further cardiovascular risk factors - unhealthy diet and physical inactivity — have recently been reported elsewhere for a set of (mainly middle income) countries, ${ }^{11}$ but are not integrated into our analysis because of differences in the modelling environment adopted.

\section{Methods}

This analysis follows the standardised methodology on cost effectiveness analysis set forth by the WHO-CHOICE project ${ }^{12-14}$ and builds on previous analyses of public health interventions to lower systolic blood pressure and cholesterol ${ }^{15}$ and of tobacco use. ${ }^{16} \mathrm{We}$ provide an overview of the methods and data used to carry out and update these earlier analyses and a more detailed description of modelling assumptions and data sources adopted for previously unpublished analyses (management of cardiovascular disease and diabetes).

In common with other papers in this and a previous WHO-CHOICE series ${ }^{17}$ cost effectiveness modelling was carried out for two WHO reporting sub-regions, one in Africa (countries with high child and very high adult mortality, henceforth denoted "AfrE") and the other in South East Asia (countries with high child and adult mortality, henceforth denoted "SearD"). Information on the countries pertaining to these two WHO epidemiological sub regions can be found in appendix 1 on bmj.com. Results for other WHO reporting regions can be viewed at the WHO-CHOICE website (www. who.int/choice); the models used have been designed for subsequent contextualisation by individual member states.

\section{Interventions}

A range of strategies for prevention and control were considered; where it was clinically meaningful to do so, we also assessed combination strategies. Table $1 \Downarrow$ lists all single interventions included in this analysis. Interventions were selected according to the strength of evidence supporting their effectiveness as well as recommendations from published guidelines (see appendices 2-4 on bmj.com). Effectiveness of interventions was sought using the best available evidence reported in international literature. Source data for intervention effectiveness included meta-analyses, systematic reviews, clinical trials, and observational studies (appendices 2-4).

Tobacco control strategies-Prevention of cardiovascular disease-as well as lung cancer and chronic obstructive pulmonary disease-via enhanced tobacco control efforts included key strategies of the WHO Framework Convention for Tobacco Control to reduce demand (current and increased taxation, legislated restrictions on smoking in public places, comprehensive bans on advertising of tobacco products, information dissemination through health warning labels, counter advertising, and various consumer information packages). Personal health interventions include nicotine replacement therapy and physician advice. Appendix 2 on bmj.com documents the efficacy, non-compliance, and target coverage levels of these measures.

Cardiovascular disease interventions-Primary prevention strategies cover both population-wide and individual level interventions aimed at reducing the risk of coronary heart disease and cerebrovascular disease through the voluntary or regulated reduction in dietary salt intake, control of blood pressure and cholesterol with drugs, and combination drug therapy for people at an absolute (as opposed to relative) risk of experiencing a cardiovascular disease event over the next 10 years $>25 \%$. $^{15}$ The multidrug regimen consisted of four generic drugs-a $\beta$ blocker, a diuretic, a statin, and aspirin (because of the risk of gastrointestinal bleeding in a group of patients, debate continues about the overall risk:benefit ratio of aspirin in primary prevention of cardiovascular disease). Management strategies focus on acute care of myocardial infarction and stroke in the inpatient setting, covering both surgical and drug interventions. Secondary and tertiary prevention interventions concern the long term treatment of patients with a previous myocardial infarction or stroke with the aim of reducing the risk of a subsequent event and the occurrence of more severe stages of the disease. Interventions for the management of symptomatic left ventricular systolic dysfunction in patients with a previous myocardial infarction are also included since this condition is common in patients with a previous myocardial infarction. Heart failure interventions are intended for patients in stage $C$ of the 
disease according to the American College of Cardiology and American Heart Association classification of chronic heart failure progression. ${ }^{18}$ Appendix 3 on bmj.com provides a list of the cardiovascular disease intervention strategies assessed, together with estimates of their effect on reducing the risk, incidence or fatality of disease. All interventions were assessed at a treatment coverage level of $80 \%$.

Diabetes interventions-For managing type 1 and type 2 diabetes, we focused on diabetes cases and the sequelae covered by the Global Burden of Disease study (blindness due to retinopathy, neuropathy, and diabetic foot and amputation). ${ }^{19}$ Key interventions assessed were standard and intensive approaches to glycaemic control, screening for retinopathy and subsequent treatment as needed, and screening for neuropathy plus associated preventive foot care (appendix 4 on bmj.com provides a more detailed description of these interventions and how they were modelled). A uniform $80 \%$ treatment coverage was also used in order to facilitate comparison with cardiovascular disease results.

The large majority of interventions analysed are drug based. Current availability of drugs to treat chronic diseases ranges from $36 \%$ to $55 \%$ in low and middle income countries in the public and private sector, respectively. ${ }^{20}$ In Bangladesh, Malawi, and Nepal—specific countries in the regions studied-the availability of chronic disease drugs ranges from $5 \%$ to $37.5 \%{ }^{21}$ Cardiac units to perform angioplasty are available in hospitals in the following countries in AfrE: Kenya, Tanzania,

Mozambique, South Africa, and Ivory Coast. ${ }^{22}$ Taking India as a country example for SearD, there are 220 hospitals capable of performing percutaneous angioplasty, located in the main cities. $^{23}$

We have not been able to include all possible interventions in this analysis because of lack of information on either the impact of the treatment or the underlying epidemiological data required for determining treatment effectiveness. Renal disease and cardiovascular disease, for example, were not specified as sequelae for diabetes in the Global Burden of Disease study of 2004, so we have not assessed key interventions relating to them (including the prevention of diabetes through reduction of risk of cardiovascular disease, management of cardiovascular complications among diabetic patients, and treatment of diabetic nephropathy with angiotensin converting enzyme (ACE) inhibitors). Other excluded interventions that may have a positive health impact include those for preventing rheumatic heart disease or angina pectoris and treatment of refractory end stage heart failure, early diastolic and systolic dysfunction, and concomitant diseases such as arrhythmia and cardiac valve disorders. The treatment of complications of acute events (hypotension, pulmonary congestion, cardiogenic shock, etc) and diagnostic or prognostic interventions performed during management of an acute event were beyond the scope of this analysis.

\section{Modelling approach}

WHO-CHOICE employs an epidemiological, population based approach to the assessment of health outcomes (see general appendix on bmj.com). Along with background birth, population, and mortality rates, observed rates of disease incidence, prevalence, and mortality - drawn from the Global Burden of Disease database ${ }^{19}$ and shown in table $2 \Downarrow$ - are entered into a state transition model in order to establish the total number of years of healthy life experienced over the ( 100 year) lifetime of a defined population. ${ }^{24}$ The model is successively run in order to calculate the additional number of healthy years lived by the population-equivalent to the number of disability adjusted life years (DALYs) averted - after the implementation of a single or combined health intervention, compared with a baseline or null scenario of no interventions for the disease in question. This null scenario was determined by back calculating incidence and case fatality rates using intervention effect sizes and current coverage rates (that is, epidemiological rates are adjusted upwards to reflect the absence of any effective intervention). Interventions are taken to be implemented for a period of 10 years, after which epidemiological rates go back to their counterfactual level of no intervention. Consistent with the WHO Global Burden of Disease study, DALYs are discounted (at 3\% per year) and age weighted.

The specific benefits of tobacco control measures on population health were estimated through the impact of reduced smoking on the tobacco attributable incidence of cardiovascular disease, respiratory disease, and mortality from various forms of cancer. We modelled the increase in taxation that would reduce smoking prevalence by $10 \%$ on the basis of data on tobacco taxation from previous WHO and World Bank studies. ${ }^{25}$ The effect of price changes on consumption was estimated from information about price elasticities of demand for tobacco products (the percentage change in consumption resulting from a $1 \%$ increase in price). For a $10 \%$ rise in price due to tobacco taxes, consumption generally falls by $8-10 \%$ in low and middle income countries. ${ }^{26}{ }^{27}$ We calculated that the prevalence elasticity (the percentage change in smoking prevalence resulting from a $1 \%$ increase in price) was half the total price elasticity of demand, because at least half of the estimated effect on the demand for tobacco products results from a reduction in smoking prevalence. ${ }^{28}$ Given that current smoking prevalence is a poor proxy for the accumulated health risks of tobacco use, we used the smoking impact ratio as a marker for cumulative smoking risk. ${ }^{29}$ The smoking impact ratio captures the accumulated hazards of smoking by converting the smokers in the population analysed into equivalents of smokers in a reference population, where hazards for other diseases have been measured. The reference population used in our case was the CPS II cohort. ${ }^{30}$ We used relative risks in estimating tobacco attributable morbidity and mortality. Intervention effectiveness was assessed through changes in smoking impact ratio and relative risks of mortality and morbidity from tobacco related diseases per unit of smoking impact ratio (see table $3 \Downarrow$ for relative risk values used in the analysis).

For the primary prevention of cardiovascular disease, health effects were modelled by stochastically simulating populations specific for age and sex with the observed baseline values of ischaemic heart disease and stroke incidence and the observed distribution of risk factors (systolic blood pressure, serum cholesterol, body mass index, and prevalence of long term smokers ${ }^{15}$ ) (see table $2 \Downarrow$ ). Incidence risk is apportioned between individuals using estimates of the relative risk of modelled risk factors on cardiovascular events (table $3 \Downarrow$ ). Population level incidence of ischaemic heart disease and stroke is recalculated after applying the impact of the intervention on the individual risk factor values for those receiving the intervention.

For acute myocardial infarction and stroke, health effects were modelled through their impact on case fatality in hospital and after discharge up to 28 days after the event (out of hospital case fatality rates were assumed to remain unchanged). Secondary and tertiary prevention interventions were modelled through their impact on post-28 day case fatality rates for each condition and the rate of complications attributable to ischaemic heart disease (angina, congestive heart failure). The interaction in risk between ischaemic heart disease and stroke was modelled 
using estimates of relative risk of stroke for those with previous ischaemic heart disease and vice versa from published epidemiological studies (see appendix 3 on bmj.com).

Finally, for managing diabetes and its complications, intervention health effects were expressed in terms of composite disability weights that reflect varying distributions of different health states (diabetes without complications, neuropathy, lower extremity amputation, background retinopathy, proliferative diabetic retinopathy plus macular oedema, and blindness due to retinopathy). These six disease states reflect the progression of diabetes along the long term consequences of eye and foot disease. To derive a composite disability weight for each intervention, we simulated the evolution of a closed population cohort of people aged $>15$ years over 100 years via a health state model (MiniMod, see appendix 4 on bmj.com for further details).

\section{Intervention costs}

We pursued an ingredients approach to costing, meaning that information on the quantities of all services and goods required for the delivery of an intervention as well as data on their unit costs were sought. The total cost of an intervention is the product of these quantities and their respective unit costs. Particular attention was given to maintaining consistency of the information on resource use with that described in the articles selected as source of effectiveness for the interventions. Costs were calculated for a 10 year period of implementation (subsequently discounted annually by $3 \%$ ) and expressed in international dollars for 2005. An international dollar is a hypothetical currency that is used as a means of comparing costs taking into account differences in purchasing power. One international dollar (\$Int1) buys the same quantity of healthcare resources in Kenya or India as it does in the United States. As reference, \$Int1 is worth US\$0.44 and US\$0.32 in sub-Saharan Africa and South East Asia regions, respectively. We considered both patient and programme costs. Patient costs included drugs, laboratory tests, and inpatient and outpatient visits. A detailed description of resource quantities used at the patient level is given for each diabetes intervention in appendix 4 and for each cardiovascular disease intervention in appendix 5 on bmj.com. Programme costs included all resources required for the implementation and maintenance of interventions, such as administration and planning, media and communications, law enforcement activities, training, evaluation, and monitoring. Population-wide measures for reducing salt intake or tobacco use involve costs exclusively at the programme level and are documented elsewhere. ${ }^{25}$ Costing of these interventions was performed using WHO-CHOICE programme costing templates and world regional pricing databases (www.who.int/choice).

\section{Handling of cost effectiveness data and uncertainty}

Dividing the total implementation costs of each intervention by its effects generates a simple cost effectiveness ratio, relative to a comparator situation of no intervention. In addition to average cost effectiveness ratios, incremental cost effectiveness ratios are reported for the successive set of interventions that would be selected at expanding levels of resource availability, starting with the intervention with the lowest cost per DALY averted, then moving to the next most cost effective combination intervention out of the remaining available set of interventions. An intervention that is more costly or less effective than other more efficient interventions is denoted as dominated.
All interventions are imbued with a certain degree of uncertainty. To handle this aspect of reporting for such a wide range of interventions, we first placed intervention results on a logarithmic scale, with a view to ascertaining order of magnitude differences in cost effectiveness (such as \$Int10-100 versus \$Int100-1000 per DALY averted). Secondly, we categorised results according to a defined set of cost effectiveness thresholds: WHO-CHOICE denotes an intervention as "cost effective" if it produces a healthy year of life for less than three times the gross domestic product (GDP) per capita, and as "very cost effective" if it produces a healthy year of life for less than the GDP per capita. Finally, for the subset of intervention strategies that were not dominated by others and therefore fall on the cost effectiveness frontier, we undertook a probabilistic uncertainty analysis using the MCLeague software program. ${ }^{32}$ We also assessed the impact of removing age weights or discounting on baseline results via one way sensitivity analysis.

\section{Results}

A total of 123 single and combined intervention strategies were assessed (36 for tobacco control, 77 for cardiovascular disease, and 10 for diabetes). The annual cost, effect, and cost effectiveness for all interventions are provided in appendix 6 on bmj.com, and are shown graphically in figures $1 \Downarrow$ and $2 \Downarrow$. Costs (\$Int) and effects (DALYs averted) have been calculated for a standardised population of one million people to allow for easier comparison between different geographical regions.

\section{Intervention effects}

The health impact of assessed interventions at the population level varied dramatically, ranging from 10 to $>7000$ DALYs averted annually per million population (see figs $1 \Downarrow$ and $2 \Downarrow$ ). The largest effects were found among drug strategies directed towards the prevention and control of raised blood pressure or cholesterol. At a treatment coverage level of $80 \%$, drug treatment for those with hypertension (systolic blood pressure $>140$ or $>160 \mathrm{~mm} \mathrm{Hg}$ ) and combined drug therapy for people with a 5-35\% risk of experiencing a cardiovascular event in the next 10 years are estimated to avert between 2000 and 7000 DALYs per million population in both the African and South East Asian sub-regions (so in India alone, with over a billion inhabitants, this would equate to at least 2-5 million DALYs averted). A comprehensive set of demand reduction measures for tobacco control-such as that contained in the MPOWER package (acronym for the activities monitor, protect, offer, warn, enforce, and raise $)^{33}$-also has the potential to yield large health benefits, particularly where the tobacco epidemic is more advanced (such as in South East Asian sub-region SearD, where population level health gains are five times greater than in the African sub-region).

Acute care and secondary prevention strategies for people who have had a heart attack or stroke fall into the range of 10-1000 DALYs averted per million population, and again show greater expected benefits in the South East Asian population (because of the higher prevalence of disease, table $2 \Downarrow$ ). For acute myocardial infarction, treatment in hospital with aspirin alone averts 59 DALYs per million population in the African sub-region and 243 in the South East Asian sub-region. Health gains are doubled when this strategy is combined with provision of thrombolysis with streptokinase, and tripled if percutaneous transluminal coronary angioplasty can also be made available; marginal additional health gains can be secured by also making use of antihypertensive drugs ( $\beta$ blockers and ACE inhibitors). Acute treatment for stroke with aspirin or by provision of an 
organised stroke unit generates modest outcomes ( $<50$ DALYs saved per million population). For secondary prevention, the most effective measures assessed revolved around multiple drug therapy: for post-acute stroke, aspirin and a statin, with the addition of an ACE inhibitor and diuretic for greatest gains (>700 DALYs averted per million population); for post-acute ischaemic heart disease, a combination of aspirin, $\beta$ blocker, statin, and ACE inhibitor. Use of loop diuretics, exercise training, and drug treatment of hypertension was estimated to be the single most effective option for reducing the mortality risk among patients with congestive heart failure (see appendices 3 and 5 on bmj.com).

Concerning the management of diabetes and the specified sequelae included in the analysis, the most effective strategy of those assessed was intensive glycaemic control combined with a programme of retinopathy screening and photocoagulation (1529 and 3710 DALYs averted per million population in AfrE and SearD, respectively). On its own, intensive glycaemic control was found to generate $19-23 \%$ more health gain than conventional glycaemic control (appendix 6 on bmj.com). The programme of neuropathy screening and preventive foot care was the least effective strategy.

\section{Intervention costs}

Total costs of implementing an intervention over a 10 year period were annualised and converted into per capita estimates for easier interpretation. From this public health perspective, the costs associated with delivering these interventions at a scaled up level of coverage are not high, with most falling well below \$Int 1 per capita (see figs $1 \Downarrow$ and $2 \Downarrow$ ). Some interventions are very low cost (<\$nt0.20 per capita), not just population based measures such as salt reduction and tobacco taxation, but also many of the acute care and secondary prevention measures aimed at individuals who have already experienced a heart attack or stroke. Although the overall costs of these interventions are similarly low, it must be remembered that there are large differences in the number of exposed or treated people (for example, acute myocardial infarction care is targeted on less than $1 \%$ of the total population, compared with $80 \%$ for regulatory tobacco control measures). This explains why drug treatment strategies for individuals at an elevated but not very high risk of cardiovascular disease (such as those with systolic blood pressure $>140 \mathrm{mmHg}$ or serum cholesterol $>5.7 \mathrm{mmol} / \mathrm{L}$ ) are among the most expensive strategies to implement at the population level (\$Int1-3 per capita); there are simply a lot of people who meet these criteria ( $>25 \%$ of all men aged $\geq 60$ years, for example). The total number of beneficiaries and the annual cost per treated case for the full range of cardiovascular disease treatment strategies are presented in appendix 6 , from which it can be seen that costs per treated case for acute care interventions generally fall in the range of \$Int500-3000, while population-wide primary prevention strategies cost $\$$ Int $30-80$ per case. An intensive glycaemic control programme for people with diabetes is also relatively costly (>\$nt 2 per capita), due to the many resources that are consumed in its implementation (as described in appendix 4).

\section{Intervention cost effectiveness}

As shown by the diagonal bands in figures $1 \Downarrow$ and $2 \Downarrow$, average cost effectiveness ratios were found to fall in the range of \$Int100-10 000 per DALY averted (two orders of magnitude difference). Within the more restricted range of \$Int100-1000 per DALY averted, interventions appear for each of the diseases and risk factors considered in the analysis. Using average GDP per capita (which in both sub-regions is close to \$Int2000) as a threshold for considering an intervention to be highly cost effective, we found the great majority of interventions assessed here meeting that criterion. Exceptions include the treatment of acute myocardial infarction with $\beta$ blockers or ACE inhibitors alone, treatment of acute ischaemic stroke with aspirin, provision of organised stroke unit care, and nicotine replacement therapy; these interventions have a cost effectiveness ratio more than three times the average per capita income in these regions (>\$nt6000) and are considered relatively cost ineffective.

In the African sub-region, the most cost effective interventions (average cost effectiveness ratio $<\$$ Int200 per DALY averted) were those that targeted individuals at $>25 \%$ absolute risk of having a cardiovascular event in the next 10 years, either on their own or in combination with an efficient set of secondary prevention measures. These were also among the most efficient interventions in the South East Asian sub-region, as well as other strategies such as tobacco control measures, retinopathy screening and treatment, and the management of congestive heart failure with diuretics. Even if the cost of implementing these interventions were doubled and effect sizes halved, the average cost effectiveness ratios would still be $<\$$ Int 1000 per DALY averted.

The costs, effects, and cost effectiveness of all the "dominant" interventions - that is, those that are more effective or less costly than other competing strategies - are shown in table $4 \Downarrow$. The interventions are presented in descending order, starting with the most cost effective intervention in each disease cluster. As more resources become available, other cost effective interventions could be purchased. These next best options, at situations of increased resource availability, are presented in the table in downward sequence. Incremental cost effectiveness ratios are also provided for each cluster of interventions, which give the additional cost needed to secure one extra healthy life year as successively less cost effective strategies are entered into the mix. The probabilistic uncertainty analysis depicted in figures $3 \Downarrow$ and $4 \Downarrow$ also show that these interventions remain highly cost effective (cost effectiveness ratio <\$Int2000 per DALY averted) even after allowing for plausible variations in costs and effects. A one way sensitivity analysis revealed that removing age weights from the estimation of DALYs has a modest positive impact on baseline results (average cost effectiveness ratio values fall by $8-25 \%$ ); removing discounting as well has a larger influence, increasing health outcomes for treatment strategies by at least $40 \%$ and preventive measures by more than $100 \%$ and thereby lowering cost effectiveness values markedly (by a third to a half).

\section{Discussion}

\section{Main findings}

We have quantified the health effects, costs, and cost effectiveness of a broad range of preventive and management strategies for reducing the risk of cardiovascular disease burden, as well as a number of specific treatment measures for diabetes and its complications. These results were obtained by means of a dynamic population model, using consistent demographic and epidemiological data of the populations studied, allowing a more precise prediction of the behaviour of the disease and consequently of the health and economic impact of the strategies studied.

Our results provide important information about prevention and management of cardiovascular disease in the two settings studied, for both individual and population health. From the individual viewpoint, the effectiveness of interventions increases with the risk of the target population, with greatest gains per 
beneficiary seen among the more effective strategies for managing an acute cardiovascular disease event (management of acute myocardial infarction with aspirin, blood pressure lowering drugs, and reperfusion with percutaneous transluminal coronary angioplasty). The treatment effect decreases as the risk lowers, such that the lowest health gain per beneficiary is attained through health promotion interventions targeting susceptible individuals regardless of their risk factor or disease status.

From a population health perspective, however, the small effects achieved by strategies targeting large, lower risk groups may end up generating more overall health gain (as seen from this analysis). As a consequence, from this perspective, health promotion and primary prevention interventions, such as combined hypertension and lipid lowering drugs plus aspirin for individuals with a cardiovascular disease risk $>25 \%$, are more effective than acute care and secondary prevention interventions. Thus, the combination of individual and population-wide strategies is required for a complete risk reduction. ${ }^{34}$ In this analysis these combinations (cardiovascular disease interventions CVD-69-71, 73-76, and 78 (see appendix 6 for explanation)) were highly effective, averting more than 5000 DALYS annually per million population.

With respect to the cost of interventions, the cost per individual increases as the risk level of the target group rises, mainly due to the increased need for and complexity of healthcare services (particularly inpatient hospital admission). At the other end of the spectrum, population-wide measures aimed at reducing tobacco use, blood pressure, and blood cholesterol make no use of healthcare facilities and therefore tend to be inexpensive to implement.

Differences between the individual and population health perspectives are reconciled when comparing interventions in terms of their cost effectiveness (total costs divided by total health gains). Our analysis indicates that most of the interventions studied were highly cost effective, meaning they would generate one healthy year of life at a cost of less than the GDP per capita of the region in question (around \$Int2000 in the two regions considered here). Out of the large collection of highly cost effective options, we identified which interventions offer the best monetary value and which could be considered for prioritised implementation or scale up, including demand reduction strategies of the Framework Convention for Tobacco Control, combination drug therapy for individuals with a $>25 \%$ chance of experiencing a cardiovascular disease event over the next decade, and the combination of this population-wide intervention with individual treatment of acute myocardial infarction with drugs and reperfusion or with individual multidrug regimens for the secondary prevention of post-acute ischaemic heart disease and stroke. These interventions have been identified as essential cardiovascular disease interventions that need to be financed as a first step to universal coverage. ${ }^{3435}$ In the case of diabetes, we have identified retinopathy screening and glycaemic control for patients with diabetes as a cost effective intervention that needs to be given priority, in addition to interventions such as cardiovascular risk reduction in diabetes and screening for albuminuria for prevention of nephropathy that have been identified in other studies as cost effective options. ${ }^{36-41}$ Although intensive glycaemic control was highly cost effective in the regions analysed, the effects of this intervention may vary within different patient subgroups (men $v$ women, age, baseline $\mathrm{HbA}_{1 c}$, comorbidities) ${ }^{42}$ so these results should be interpreted with caution.

\section{Policy implications}

The findings from this economic analysis should be used as a guide for decision makers and are not prescriptive, since other factors-such as the epidemiology of the disease, health infrastructure, and government support-should be taken into account. In particular, this analysis provides results at regional levels, using regional information on epidemiology and resource use. Although the WHO-CHOICE framework provides results that are generalisable across settings, it should be recognised that information on epidemiology and costs used can be expected to vary among countries within the same region, even more so among countries from different regions. Decision makers who wish to contextualise these results to their specific country should assess the need to modify these parameters (effectiveness, costs, coverage, disability weights, etc) based on national data in order to more accurately reflect efficiency considerations in their own context. Country level contextualisation of the various analytical models - as has been undertaken in Argentina, Estonia, Mexico, and Vietnam, for example ${ }^{103-45}$ - provides a useful process for generating more local evidence for national decision makers and fostering policy dialogue.

To allow for a meaningful comparison of all interventions analysed across the different disease clusters, the standard approach taken here was to report results at an $80 \%$ coverage level. Adopting a uniform coverage level is relevant for identifying the pattern of best choices of interventions in terms of efficiency. However, implementation at this coverage level might not be feasible for some interventions in certain locations. Modellers and decision makers can adjust coverage level and other parameters during country contextualisation of this analysis to better reflect the situation at a country level.

The health and economic impact of public health interventions could be broad and may fall outside the health sector. The assessment of outcomes of public health interventions here analysed (such as demand reduction strategies for tobacco and food salt reduction via legislation) has been limited to benefits within the health sector, following the perspective and methodology of cost effectiveness analysis. Other non-health benefits that might be important, such as productivity gains, as well as the quantification of cost consequences outside the health sector would need to be explored by means of other intersectoral approaches. $^{46}$

\section{Study limitations and future research}

Our results represent aggregate regional estimates based on the best available sources in published international literature. Many of the effectiveness and some of the resource use values used in this analysis are derived from estimates or standards obtained from developed countries in the absence of data from the less developed regions analysed. Although other data used in this analysis - such as disease epidemiology, demography, intervention use, adherence, and capacity use - are region specific and contribute to more precise cost effectiveness estimates, similar results in specific locations may not be assumed since outcomes or resource use estimates may vary from developed to developing countries. For instance, $61 \%$ case fatality reduction with percutaneous transluminal coronary angioplasty may not be achievable in some hospitals in developing countries. Although we have performed uncertainty analysis around key effect and cost estimates, for better precision on these estimates, analysts in a specific low or middle income country are encouraged to adjust parameters to reflect context specific situations based on local quality data. Results from high 
quality research in developing countries would be required for this purpose.

Because of the sheer number of assessed interventions, it was practicable only to show graphically probabilistic uncertainty estimates for interventions that are less costly or more effective than other less efficient interventions, thereby omitting other interventions with a lower but still real probability of being cost effective at defined threshold levels.

Finally, and with the exception of salt reduction, we have not been able to integrate here the impact of diet and physical activity in addressing the burden of cardiovascular disease. A recent collaborative study between the Organisation for Economic Co-operation and Development (OECD) and the WHO — of intervention cost effectiveness for tackling unhealthy diets, physical inactivity, and obesity - adopted a micro-simulation approach to disease modelling, assumed a different implementation period, and compared intervention impact with the current situation (rather than no intervention), thereby hindering comparability with our study results. Nevertheless, results from this study of interventions for improved diet and physical activity indicate that there are several population based prevention policies-covering improved awareness and information, appropriate fiscal measures, and enhanced regulatory mechanisms - that, from an efficiency point of view, might usefully be added to the measures identified for the risk factors explicitly considered here (tobacco use, high blood pressure, and elevated cholesterol).

In terms of future research requirements, the standout issue is the need for a more complete single model that is capable of simultaneously dealing with all cardiovascular risk factors and their interactions. Since diabetes increases the risk of cardiovascular disease, for example, the impact of interventions for the treatment of hyperglycaemia in reducing this risk should be assessed. This analysis and previous cost effectiveness studies have focused on the influence of traditional risk factors in the development of cardiovascular events, but-because of the increasing prevalence of diabetes - an integrated diabetes-cardiovascular disease approach should be pursued in future.

Contributors: All authors contributed to the conception, design and interpretation of data. MO and DC performed the technical analysis and drafted the manuscript. All authors approved the submitted version of the manuscript. $\mathrm{MO}$ is the guarantor of the manuscript.

Funding: None

Competing interests: All authors have completed the ICMJE uniform disclosure form at www.icmje.org/coi_disclosure.pdf (available on request from the corresponding author) and declare: no support from any organisation for the submitted work; no financial relationships with any organisation that might have an interest in the submitted work in the previous three years; no other relationships or activities that could appear to have influenced the submitted work.

$\mathrm{DC}$ and SM are staff members of the WHO. The authors alone are responsible for the views expressed in this publication, and these do not necessarily represent the decisions, policy, or views of the WHO.

Ethical approval: Not required.

Data sharing: No additional data available.

1 Abegunde DO, Mathers CD, Adam T, Ortegon M, Strong K. The burden and costs of chronic diseases in low-income and middle-income countries. Lancet2007 8:370:1929-38.

2 World Health Organization. Preventing chronic disease: a vital investment. WHO, 2005.

3 United Nations General Assembly. Special session on non-communicable diseases: political declaration of the high-level meeting of the General Assembly on the Prevention and Control of Non-communicable Diseases (document A/66/L.1). UN, 2011.

4 Stanciole AE, Ortegón M, Chisholm D, Lauer JA. Cost effectiveness of strategies to combat chronic respiratory diseases in sub-Saharan Africa and South East Asia: mathematical modelling study. BMJ 2012;344:e608.
5 Ginsberg G, Lauer JA, Zelle S, Baeten S, Baltussen R. Cost effectiveness of strategies to combat breast, cervical, and colorectal cancer in sub-Saharan Africa and South East Asia: mathematical modelling study. BMJ 2012;344:e614.

6 Chisholm D, Saxena S. Cost effectiveness of strategies to combat neuropsychiatric conditions in sub-Saharan Africa and South East Asia: mathematical modelling study. BMJ 2012;344:e609.

7 Baltussen R, Smith A. Cost effectiveness of strategies to combat vision and hearing loss in sub-Saharan Africa and South East Asia: mathematical modelling study. BMJ 2012;344:e615.

8 Chisholm D, Naci H, Hyder AA, Tran NT, Peden M. Cost effectiveness of strategies to combat road traffic injuries in sub-Saharan Africa and South East Asia: mathematical modelling study. BMJ 2012;344:e612.

9 Chisholm D, Baltussen R, Evans DB, Ginsberg G, Lauer J, Lim S, et al. What are the priorities for prevention and control of non-communicable diseases and injuries in sub-Saharan Africa and South East Asia? BMJ 2012;344:e586.

10 Salomon JA, Carvalho N, Gutiérrez-Delgado C, Orozco R, Mancuso A, Hogan DR, et al. Intervention strategies to reduce the burden of non-communicable diseases in Mexico: cost effectiveness analysis. BMJ 2012;344:e355.

11 Cecchini M, Sassi F, Lauer JA, Lee YY, Guajardo-Barron V, Chisholm D. Tackling of unhealthy diets, physical inactivity, and obesity: health effects and cost-effectiveness. Lancet 2010;376:1775-84.

12 Murray CJ, Evans DB, Acharya A, Baltussen RM. Development of WHO guidelines on generalized cost-effectiveness analysis. Health Econ 2000;9:235-51.

13 Tan-Torres Edejer TBR, Adam T, Hutubessy R, Acharya A, Evans DB, Murray CJL. Making choices in health: WHO guide to cost-effectiveness analysis. World Health Organization, 2003.

14 Evans DB, Edejer TT, Adam T, Lim SS. Methods to assess the costs and health effects of interventions for improving health in developing countries. BMJ 2005;331:1137-40.

15 Murray CJ, Lauer JA, Hutubessy RC, Niessen L, Tomijima N, Rodgers A, et al. Effectiveness and costs of interventions to lower systolic blood pressure and cholesterol: a global and regional analysis on reduction of cardiovascular-disease risk. Lancet 2003;361:717-25.

16 Shibuya K, Ciecierski C, Guindon E, Bettcher DW, Evans DB, Murray CJ. WHO Framework Convention on Tobacco Control: development of an evidence based global public health treaty. BMJ 2003;327:154-7.

17 Evans DB, Lim SS, Adam T, Edejer TT. Evaluation of current strategies and future priorities for improving health in developing countries. BMJ 2005;331:1457-61.

18 Hunt SA, Baker DW, Chin MH, Cinquegrani MP, Feldman AM, Francis GS, et al. ACC/AHA guidelines for the evaluation and management of chronic heart failure in the adult: executive summary. A report of the American College of Cardiology/American Heart Association Task Force on Practice Guidelines (committee to revise the 1995 Guidelines for the Evaluation and Management of Heart Failure). J Am Coll Cardiol 2001;38:2101-13.

19 Murray C, Lopez A, Mathers C, Stein C. The global burden of disease 2000 project: aims, methods and data sources. World Health Organization, 2001.

20 Abegunde D. Essential medicines for non communicable disease. World Health Organization, 2006

21 Mendis S, Fukino K, Cameron A, Laing R, Filipe A, Khatib O, et al. The availability and affordability of selected essential medicines for chronic diseases in six low- and middle-income countries. Bull World Health Organ 2007;85:279-88.

22 Pezzella AT. Global expansion of cardiothoracic surgery-the African challenge. 2011. www.ichfund.org/Publications/GlobalExpansionCardiothoracicSurgery.htm.

23 Karthikeyan G, Xavier D, Prabhakaran D, Pais P. Perspectives on the management of coronary artery disease in India. Heart 2007;93:1334-8.

24 Lauer JA, Rohrich K, Wirth H, Charette C, Gribble S, Murray CJ. PopMod: a longitudinal population model with two interacting disease states. Cost Eff Resour Alloc 2003;1:6.

25 Asaria P, Chisholm D, Mathers C, Ezzati M, Beaglehole R. Chronic disease prevention health effects and financial costs of strategies to reduce salt intake and control tobacco use. Lancet 2007:370:2044-53.

26 World Health Organization. Reducing risks to health, promoting healthy life. The world health report 2002. Some strategies to reduce risk (chapter 5). WHO, 2002.

27 Jha P, Chaloupka FJ. The economics of global tobacco control. BMJ 2000;321:358-61.

28 Jha P, Chaloupka FJ, Corrao M, Jacob B. Reducing the burden of smoking world-wide: effectiveness of interventions and their coverage. Drug Alcohol Rev 2006-25:597-609.

29 Ezzati M, Lopez AD. Estimates of global mortality attributable to smoking in 2000. Lancet 2003;362:847-52.

30 Steenland K, Thun M, Lally C, Heath C Jr. Environmental tobacco smoke and coronary heart disease in the American Cancer Society CPS-II cohort. Circulation 1996;94:622-8.

31 Murray CJL, Lopez AD, eds. The global burden of disease: a comprehensive assessment of mortality and disability from diseases, injuries, and risk factors in 1990 and projected to 2020 . Harvard University Press, 1996.

32 World Health Organization. Information on the use of Monte Carlo League software program for uncertainty analysis for cost-effectiveness. 2011. www.who.int/choice/toolkit/ mc_league/en/index.html.

33 World Health Organization. WHO report on the global tobacco epidemic. The MPOWER package. 2008. www.who.int/tobacco/mpower.

34 World Health Organization. Prevention of cardiovascular disease: guideline for assessment and management of cardiovascular risk. WHO, 2007.

35 World Health Organization. Package of essential noncommunicable (PEN) disease interventions for primary care in low-income resource settings. WHO, 2007.

36 UK Prospective Diabetes Study Group. Cost effectiveness analysis of improved blood pressure control in hypertensive patients with type 2 diabetes: UKPDS 40. BMJ 1998;317:720-6.

37 Grover SA, Coupal L, Zowall H, Alexander CM, Weiss TW, Gomes DR. How cost-effective is the treatment of dyslipidemia in patients with diabetes but without cardiovascular disease? Diabetes Care 2001;24:45-50.

38 Mihaylova B, Briggs A, Armitage J, Parish S, Gray A, Collins R. Cost-effectiveness of simvastatin in people at different levels of vascular disease risk: economic analysis of a randomised trial in 20,536 individuals. Lancet 2005;365:1779-85

39 CDC Diabetes Cost-effectiveness Group. Cost-effectiveness of intensive glycemic control, intensified hypertension control, and serum cholesterol level reduction for type 2 diabetes. JAMA 2002;287:2542-51.

40 Manns B, Hemmelgarn B, Tonelli M, Au F, Chiasson TC, Dong J, et al. Population based screening for chronic kidney disease: cost effectiveness study. BMJ 2010;341:c5869. 


\section{What is already known on this topic}

Cardiovascular disease, diabetes, and the associated risk factor of smoking impose a high epidemiological and economic burden on low and middle income countries

A range of effective strategies are available to counteract these diseases that could bring considerable health gains if they were implemented

Evidence on the cost effectiveness of these interventions is needed to develop a policy framework for combating cardiovascular disease, diabetes, and associated risk factors

\section{What this study adds}

A lifetime population model was used to assess the cost effectiveness of 123 single or combined prevention and treatment strategies for cardiovascular disease, diabetes, and smoking

The most cost effective interventions to be considered for prioritised implementation in two regions of the world with the highest burden of chronic diseases include strategies to reduce tobacco demand; combination drug therapy for people with a $>25 \%$ chance of experiencing a cardiovascular event over the next decade, either alone or together with multidrug regimens for secondary prevention of post-acute ischaemic heart disease and stroke; and retinopathy screening and glycaemic control for patients with diabetes

41 Hoerger TJ, Wittenborn JS, Segel JE, Burrows NR, Imai K, Eggers P, et al. A health policy model of CKD: 2. The cost-effectiveness of microalbuminuria screening. Am J Kidney Dis 2010;55:463-73

42 Ray K, Seshasai S, Wijesuriya S, Sivakumaran R, Nethercott S, Preiss D, et al. Effect of intensive control of glucose on cardiovascular outcomes and death in patients with diabetes mellitus: a meta-analysis of randomised controlled trials. Lancet 2009;373:1765-72.

43 Rubinstein A, García Martí S, Souto A, Ferrante D, Augustovski F. Generalized cost-effectiveness analysis of a package of interventions to reduce cardiovascular disease in Buenos Aires, Argentina. Cost Eff Resour Alloc 2009;7:10

44 Lai T, Habicht J, Reinap M, Chisholm D, Baltussen R. Costs, health effects and cost-effectiveness of alcohol and tobacco control strategies in Estonia. Health Policy 2007;84:75-88.

$45 \mathrm{Ha}$ DA, Chisholm D. Cost-effectiveness analysis of interventions to prevent cardiovascular disease in Vietnam. Health Policy Plan 2011;26:210-22.

46 Weatherley H, Drummond M, Claxton K, Cookson R, Ferguson B, Godfrey C, et al. Methods for assessing the cost-effectiveness of public health interventions: key challenges and recommendations. Health Policy 2009;93:85-92.
47 Mathers C, Ma Fat D, Boerma JT. The global burden of disease: 2004 update . World Health Organization, 2008

48 Ezzati M, Lopez AD, Rodgers A, Murray CJL, eds. Comparative quantification of health risks: global and regional burden of disease attributable to selected major risk factors. World Health Organization, 2004

Accepted: 26 October 2011

\section{Cite this as: BMJ 2012:344:e607}

This is an open-access article distributed under the terms of the Creative Commons Attribution Non-commercial License, which permits use, distribution, and reproduction in any medium, provided the original work is properly cited, the use is non commercial and is otherwise in compliance with the license. See: http://creativecommons.org/licenses/bync/2.0/ and http://creativecommons.org/licenses/by-nc/2.0/legalcode. 


\section{Tables}

Table 1| List of single interventions considered in cost effectiveness analysis of strategies to combat cardiovascular disease, diabetes, and tobacco related disease in WHO sub-Saharan African sub-region AfrE and South East Asian sub-region SearD

\begin{tabular}{|c|c|}
\hline Intervention and code & Description \\
\hline \multicolumn{2}{|l|}{ Tobacco control use } \\
\hline TOB-1: Raise taxes on tobacco & Current excise taxation $(\sim 40 \%)$ \\
\hline TOB-2: Raise taxes on tobacco & Increased excise taxation (60\%) \\
\hline TOB-3: Enforce bans on tobacco advertising & Comprehensive ban on advertising of tobacco products \\
\hline TOB-4: Protect people from tobacco smoke & Clean indoor air in public places through legislation and enforcement \\
\hline TOB-5: Warn about the dangers of tobacco & Counter-advertising and warning labels \\
\hline TOB-6-8: Offer to help quit tobacco use & Nicotine replacement therapy (TOB-6), brief advice (TOB-7), counselling (TOB-8) \\
\hline \multicolumn{2}{|l|}{ Cardiovascular disease } \\
\hline \multicolumn{2}{|l|}{ Primary prevention, population-wide: } \\
\hline $\begin{array}{l}\text { CVD-1: Salt reduction in processed foods via voluntary agreement } \\
\text { with industry }\end{array}$ & $\begin{array}{l}\text { Cooperation between government and food industry for stepwise decrease in salt content } \\
\text { of processed foods and for labelling }\end{array}$ \\
\hline CVD-2: Salt reduction in processed foods via legislation & Legislation to decrease salt content in processed foods and appropriate labelling \\
\hline CVD-3: Health education through mass media & $\begin{array}{l}\text { Health education through broadcast and print media focusing on body mass index and } \\
\text { cholesterol concentrations }\end{array}$ \\
\hline \multicolumn{2}{|l|}{ Primary prevention, targeting individuals: } \\
\hline CVD-4, 5: Hypertension treatment and education & $\begin{array}{l}\text { Standard regimen of } \beta \text { blocker + diuretic for systolic blood pressure }>160 \mathrm{~mm} \mathrm{Hg} \text { (CVD-4) } \\
\text { or }>140 \mathrm{~mm} \mathrm{Hg} \text { (CVD-5) }\end{array}$ \\
\hline $\begin{array}{l}\text { CVD-6, 7: Treatment for high cholesterol concentrations and } \\
\text { education }\end{array}$ & Statins for total cholesterol concentrations $>6.2 \mathrm{mmol} / \mathrm{L}$ (CVD-6) or $>5.7 \mathrm{mmol} / \mathrm{L}$ (CVD-7) \\
\hline $\begin{array}{l}\text { CVD-8-11: Treatment based on absolute risk of a cardiovascular } \\
\text { event* in next } 10 \text { years }\end{array}$ & $\begin{array}{l}\text { Statin, diuretic, } \beta \text { blocker, + aspirin for cardiovascular risk of 35\% (CVD-8), } 25 \% \text { (CVD-9), } \\
15 \% \text { (CVD-10), or 5\% (CVD-11) }\end{array}$ \\
\hline \multicolumn{2}{|l|}{ Acute treatment: } \\
\hline CVD-14: Antithrombotic therapy & Aspirin during emergency and inhospital phases of $\mathrm{MI}$ \\
\hline CVD-16: Anti-ischaemic therapy & ACE inhibitor during emergency and inhospital phases of $\mathrm{MI}$ \\
\hline CVD-18: $\beta$ blockade therapy & $\beta$ blocker during inhospital phase of $\mathrm{MI}$ \\
\hline CVD-21: Pharmacological reperfusion & Streptokinase during emergency phase of $\mathrm{MI}$ \\
\hline CVD-22: Surgical reperfusion & Coronary percutaneous intervention (balloon angioplasty) during emergency phase of $\mathrm{MI}$ \\
\hline CVD-28: Stroke unit care & $\begin{array}{l}\text { Acute stroke and rehabilitation care coordinated by multidisciplinary team and provided in } \\
\text { hospital }\end{array}$ \\
\hline CVD-24: Antithrombotic therapy & Aspirin during emergency and inhospital phases of ischaemic stroke \\
\hline \multicolumn{2}{|l|}{ Secondary and tertiary prevention: } \\
\hline CVD-15: Antithrombotic therapy with aspirin & Long term aspirin treatment after $\mathrm{MI}$ \\
\hline CVD-17: ACE inhibitor therapy & Long term ACE inhibitor treatment after MI \\
\hline CVD-19: $\beta$ blockade therapy & Long term $\beta$ blocker treatment after $\mathrm{Ml}$ \\
\hline CVD-20: Lipid lowering therapy & Long term statin treatment after $\mathrm{Ml}$ \\
\hline CVD-23: Cardiac rehabilitation, exercise & $\begin{array}{l}\text { Exercise programme after } \mathrm{Ml} \text {, consisting of unsupervised and group exercise training sessions } \\
\text { (mainly endurance training) with initial evaluation by physician }\end{array}$ \\
\hline CVD-27: Blood pressure lowering therapy & Long term ACE inhibitor + diuretic treatment after ischaemic stroke \\
\hline CVD-25: Antithrombotic therapy & Long term aspirin treatment after stroke \\
\hline CVD-26: Lipid lowering therapy & Long term statin treatment after ischaemic stroke \\
\hline CVD-29: Diuretic therapy & Long term diuretic treatment after Ml for patients with established heart failure \\
\hline CVD-30: ACE inhibitor therapy & Long term ACE inhibitor treatment after MI for patients with established heart failure \\
\hline CVD-31: $\beta$ blockade therapy & Long term $\beta$ blocker treatment after Ml for patients with established heart failure \\
\hline CVD-32: Exercise training & $\begin{array}{l}\text { Exercise programme for established heart failure, consisting of unsupervised and group } \\
\text { exercise training sessions (endurance and resistance training) with initial evaluation by } \\
\text { physician }\end{array}$ \\
\hline
\end{tabular}




\section{Table 1 (continued)}

\section{Intervention and code}

DM-4: Retinopathy screening and photocoagulation

DM-5: Neuropathy screening and preventive foot care

\section{Description}

Detection of diabetic proliferative retinopathy and macular oedema and treatment with laser photocoagulation if suitable

Classification of feet at risk for loss of sensitivity to touch, vascular status, foot deformities, and history of ulcer or amputation; referral of high risk patients for regular examination by multidisciplinary team; provision of appropriate footware, insoles, skin and nail care, and foot care education at each review 
Table 2| Main epidemiological parameters used in analysis of cardiovascular disease, diabetes, and tobacco related disease rates in WHO sub-Saharan African sub-region AfrE and South East Asian sub-region SearD*

\begin{tabular}{|c|c|c|c|c|c|c|c|c|c|c|c|}
\hline \multirow{2}{*}{ Model parameter } & & \multicolumn{5}{|c|}{ Age groups in AfrE (years) } & \multicolumn{5}{|c|}{ Age groups in SearD (years) } \\
\hline & & $30-44$ & $45-59$ & $60-69$ & $70-79$ & $\geq 80$ & $30-44$ & $45-59$ & $60-69$ & 70-79 & $\geq 80$ \\
\hline \multicolumn{12}{|c|}{ Disease incidence (per 1000 population) } \\
\hline \multirow{2}{*}{$\begin{array}{l}\text { Ischaemic heart } \\
\text { disease }\end{array}$} & Men & 0.31 & 2.08 & 4.55 & 6.02 & 8.20 & 0.67 & 3.91 & 8.46 & 9.67 & 11.8 \\
\hline & Women & 0.14 & 1.02 & 2.53 & 3.34 & 4.72 & 0.42 & 2.00 & 5.47 & 6.82 & 6.67 \\
\hline \multirow{2}{*}{$\begin{array}{l}\text { Cerebrovascular } \\
\text { disease }\end{array}$} & Men & 0.87 & 2.93 & 6.86 & 13.0 & 20.1 & 0.34 & 2.70 & 9.38 & 14.7 & 15.3 \\
\hline & Women & 0.91 & 3.33 & 5.74 & 12.3 & 22.5 & 0.19 & 1.93 & 5.58 & 9.96 & 14.9 \\
\hline \multirow[t]{2}{*}{ Diabetes } & Men & 2.90 & 2.30 & 1.97 & 1.15 & 0.48 & 3.22 & 2.37 & 2.53 & 2.45 & 1.39 \\
\hline & Women & 2.80 & 3.00 & 1.97 & 1.17 & 0.44 & 4.02 & 2.61 & 2.15 & 1.21 & 0.29 \\
\hline \multirow[t]{2}{*}{ COPD } & Men & 0.18 & 1.43 & 4.62 & 5.43 & 9.78 & 0.54 & 2.10 & 8.30 & 9.00 & 10.9 \\
\hline & Women & 0.10 & 0.40 & 1.06 & 2.25 & 4.29 & 0.33 & 2.27 & 4.32 & 6.85 & 9.24 \\
\hline \multicolumn{12}{|c|}{ Disease prevalence (per 1000 population) } \\
\hline \multirow{2}{*}{$\begin{array}{l}\text { Ischaemic heart } \\
\text { disease }\end{array}$} & Men & 0.49 & 0.38 & 0.93 & 1.37 & 1.64 & 0.11 & 0.78 & 1.75 & 2.09 & 2.64 \\
\hline & Women & 0.02 & 0.22 & 0.63 & 0.87 & 1.16 & 0.08 & 0.40 & 1.16 & 1.46 & 1.39 \\
\hline \multirow{2}{*}{$\begin{array}{l}\text { Cerebrovascular } \\
\text { disease }\end{array}$} & Men & 0.02 & 0.07 & 0.18 & 0.38 & 0.56 & 0.01 & 0.09 & 0.18 & 0.36 & 0.61 \\
\hline & Women & 0.01 & 0.09 & 0.18 & 0.36 & 0.61 & 0.01 & 0.05 & 0.16 & 0.30 & 0.45 \\
\hline \multirow[t]{2}{*}{ Diabetes } & Men & 17.0 & 39.6 & 49.2 & 48.2 & 47.0 & 29.6 & 43.2 & 76.0 & 105 & 107 \\
\hline & Women & 15.3 & 37.3 & 47.9 & 41.4 & 34.9 & 31.4 & 49.7 & 80.2 & 91.7 & 76.5 \\
\hline \multirow[t]{2}{*}{ COPD } & Men & 1.54 & 9.20 & 27.5 & 30.2 & 31.6 & 5.92 & 45.5 & 32.1 & 45.0 & 25.6 \\
\hline & Women & 0.30 & 2.61 & 6.70 & 7.96 & 7.85 & 3.45 & 40.4 & 20.8 & 19.7 & 17.0 \\
\hline \multicolumn{12}{|c|}{ Disease mortality (per 1000 population) } \\
\hline \multirow{2}{*}{$\begin{array}{l}\text { Ischaemic heart } \\
\text { disease }\end{array}$} & Men & 0.18 & 1.56 & 5.09 & 11.8 & 23.3 & 0.37 & 2.81 & 9.32 & 18.5 & 33.9 \\
\hline & Women & 0.09 & 0.79 & 3.15 & 7.69 & 18.5 & 0.25 & 1.46 & 6.76 & 15.2 & 27.9 \\
\hline \multirow{2}{*}{$\begin{array}{l}\text { Cerebrovascular } \\
\text { disease }\end{array}$} & Men & 0.29 & 1.32 & 4.02 & 9.87 & 24.4 & 0.08 & 0.90 & 4.52 & 9.95 & 18.3 \\
\hline & Women & 0.31 & 1.27 & 4.11 & 12.2 & 31.5 & 0.05 & 0.62 & 3.69 & 9.95 & 20.4 \\
\hline \multirow[t]{2}{*}{ Diabetes } & Men & 1.13 & 1.98 & 1.74 & 1.32 & 0.45 & 0.42 & 0.97 & 2.16 & 2.57 & 1.37 \\
\hline & Women & 1.51 & 1.76 & 2.13 & 2.19 & 0.84 & 0.58 & 1.13 & 2.80 & 3.66 & 1.15 \\
\hline \multirow[t]{2}{*}{ COPD } & Men & 0.08 & 0.58 & 2.67 & 5.40 & 11.4 & 0.09 & 1.64 & 3.10 & 8.33 & 9.95 \\
\hline & Women & 0.03 & 0.20 & 0.88 & 2.13 & 4.68 & 0.05 & 1.47 & 2.02 & 4.09 & 7.55 \\
\hline \multicolumn{12}{|c|}{ Risk factor epidemiology } \\
\hline \multirow{2}{*}{$\begin{array}{l}\text { Mean systolic } \\
\text { blood pressure } \\
(\mathrm{mmHg})\end{array}$} & Men & 122 & 129 & 134 & 137 & 139 & 123 & 128 & 132 & 134 & 136 \\
\hline & Women & 118 & 128 & 135 & 139 & 140 & 120 & 126 & 131 & 134 & 137 \\
\hline \multirow{2}{*}{$\begin{array}{l}\text { Mean cholesterol } \\
\text { level }(\mathrm{mmol} / \mathrm{L})\end{array}$} & Men & 4.36 & 4.65 & 4.76 & 4.76 & 4.63 & 5.01 & 5.19 & 5.18 & 5.06 & 4.70 \\
\hline & Women & 4.28 & 4.71 & 4.94 & 5.04 & 5.07 & 5.05 & 5.44 & 5.58 & 5.63 & 5.57 \\
\hline \multirow{2}{*}{$\begin{array}{l}\text { Mean body mass } \\
\text { index }\left(\mathrm{kg} / \mathrm{m}^{2}\right)\end{array}$} & Men & 21.8 & 22.5 & 22.3 & 21.8 & 21.1 & 22.3 & 22.4 & 21.6 & 21.0 & 20.1 \\
\hline & Women & 23.2 & 23.7 & 23.6 & 23.3 & 23.0 & 21.3 & 22.1 & 22.3 & 22.2 & 21.6 \\
\hline & Men & 8.48 & 8.13 & 8.13 & 8.13 & 8.13 & 12.0 & 12.3 & 12.3 & 12.3 & 12.3 \\
\hline & Women & 9.8 & 8.00 & 8.00 & 8.00 & 8.00 & 10.9 & 10.6 & 10.6 & 10.6 & 10.6 \\
\hline Smoking & Men & 13.5 & 7.35 & 7.06 & 6.15 & 6.16 & 32.3 & 24.2 & 20.6 & 17.5 & 17.3 \\
\hline & Women & 1.19 & 1.56 & 1.38 & 0.87 & 0.67 & 0.81 & 4.09 & 3.52 & 1.45 & 0.53 \\
\hline Smoking impact & Men & 0.13 & 0.12 & 0.10 & 0.08 & 0.08 & 0.31 & 0.22 & 0.19 & 0.16 & 0.16 \\
\hline & Women & 0.06 & 0.05 & 0.04 & 0.03 & 0.03 & 0.01 & 0.04 & 0.03 & 0.01 & 0.01 \\
\hline
\end{tabular}

COPD = Chronic obstructive pulmonary disease.

*Data sources: Mathers et $\mathrm{al}^{47}$; Ezzati et $\mathrm{al}^{48}$. 
Table 3| Relative risks for disease (per unit increase in risk factor) used in analysis of cardiovascular disease, diabetes, and tobacco related disease rates in WHO sub-Saharan African sub-region AfrE and South East Asian sub-region SearD*

\begin{tabular}{|c|c|c|c|c|c|}
\hline \multirow[b]{2}{*}{ Risk factors and associated disease risks } & \multicolumn{5}{|c|}{ Age group (years) } \\
\hline & $30-44$ & $45-59$ & $60-69$ & $70-79$ & $\geq 80$ \\
\hline \multicolumn{6}{|l|}{ Systolic blood pressure (mm Hg) } \\
\hline \multicolumn{6}{|l|}{ Relative risk for disease: } \\
\hline Ischaemic heart disease & 1.07 & 1.05 & 1.03 & 1.02 & 1.01 \\
\hline Cerebrovascular disease (stroke) & 1.09 & 1.07 & 1.05 & 1.03 & 1.02 \\
\hline \multicolumn{6}{|l|}{ Cholesterol (mmol/L) } \\
\hline \multicolumn{6}{|l|}{ Relative risk for disease: } \\
\hline Ischaemic heart disease & 3.65 & 2.08 & 1.55 & 1.42 & 1.42 \\
\hline Cerebrovascular disease (stroke) & 1.48 & 1.35 & 1.25 & 1.17 & 1.09 \\
\hline \multicolumn{6}{|l|}{ Body mass index $\left(\mathrm{kg} / \mathrm{m}^{2}\right)$} \\
\hline \multicolumn{6}{|l|}{ Relative risk for disease: } \\
\hline Ischaemic heart disease & 1.11 & 1.09 & 1.05 & 1.04 & 1.03 \\
\hline Cerebrovascular disease (stroke) & 1.19 & 1.09 & 1.06 & 1.06 & 1.02 \\
\hline \multicolumn{6}{|l|}{ Smoking } \\
\hline \multicolumn{6}{|l|}{ Relative risk for disease: } \\
\hline Stroke & 3.12 & 3.12 & 1.65 & 1.65 & 1.65 \\
\hline Ischaemic heart disease and stroke & 2.43 & 2.43 & 1.84 & 1.70 & 1.38 \\
\hline Ischaemic heart disease and COPD & 6.43 & 6.43 & 5.73 & 5.73 & 5.73 \\
\hline Mortality, males (cancer effect) & 3.00 & 3.00 & 3.00 & 2.50 & 2.50 \\
\hline Mortality, females (cancer effect) & 1.80 & 1.80 & 1.80 & 1.70 & 1.70 \\
\hline
\end{tabular}


Table 4| Results for the less costly and most effective interventions to combat cardiovascular disease, diabetes, and tobacco related disease rates in WHO sub-Saharan African sub-region AfrE and South East Asian sub-region SearD

\begin{tabular}{|c|c|c|c|c|c|c|c|c|}
\hline & \multicolumn{4}{|c|}{ WHO African sub-region AfrE } & \multicolumn{4}{|c|}{ WHO Asian sub-region SearD } \\
\hline & \multirow{2}{*}{$\begin{array}{l}\text { Annual } \\
\text { DALYs } \\
\text { saved per } \\
\text { million } \\
\text { population }\end{array}$} & \multirow{2}{*}{$\begin{array}{l}\text { Annual } \\
\text { cost per } \\
\text { capita } \\
\text { (\$Int) }\end{array}$} & \multicolumn{2}{|c|}{ Cost effectiveness ratio } & \multirow{2}{*}{$\begin{array}{l}\text { Annual } \\
\text { DALYs } \\
\text { saved per } \\
\text { million } \\
\text { population }\end{array}$} & \multirow{2}{*}{$\begin{array}{l}\text { Annual } \\
\text { cost per } \\
\text { capita } \\
\text { (\$Int) }\end{array}$} & \multicolumn{2}{|c|}{ Cost effectiveness ratio } \\
\hline & & & Average* & Incremental† & & & Average* $^{\star}$ & Incremental† \\
\hline \multicolumn{9}{|c|}{ CVD prevention: control of tobacco use } \\
\hline TOB-2: Increased taxation & 687 & 0.31 & 448 & 448 & 3043 & 0.27 & 87 & 87 \\
\hline $\begin{array}{l}\text { TOB-10: As TOB-2 + clean indoor } \\
\text { air legislation }\end{array}$ & 768 & 0.42 & 552 & Dominated $\ddagger$ & 3617 & 0.36 & 98 & 156 \\
\hline $\begin{array}{l}\text { TOB-15: As TOB-10 + tobacco } \\
\text { advertising ban }\end{array}$ & 885 & 0.58 & 658 & 1384 & 4300 & 0.48 & 112 & 182 \\
\hline $\begin{array}{l}\text { TOB-27: As TOB-15 + information } \\
\text { and labelling }\end{array}$ & 1051 & 0.86 & 815 & 1645 & 5296 & 0.68 & 128 & 198 \\
\hline $\begin{array}{l}\text { TOB-35: As TOB-27 + brief advice } \\
\text { to quit }\end{array}$ & 1052 & 0.94 & 894 & Dominated $\neq$ & 5330 & 0.82 & 154 & 4176 \\
\hline $\begin{array}{l}\text { TOB-36: As TOB-27 + counselling } \\
\text { to quit }\end{array}$ & 1056 & 0.98 & 927 & 28082 & 5342 & 0.87 & 163 & 4229 \\
\hline \multicolumn{9}{|l|}{ CVD prevention and treatment } \\
\hline $\begin{array}{l}\text { CVD-29: Treatment of CHF with } \\
\text { diuretics }\end{array}$ & 96 & 0.06 & 626 & Dominated $\ddagger$ & 402 & 0.03 & 81 & 81 \\
\hline $\begin{array}{l}\text { CVD-11: Preventive multidrug } \\
\text { treatment for }>35 \% \text { risk of CVD } \\
\text { event }\end{array}$ & 3163 & 0.33 & 104 & 104 & 2984 & 0.41 & 138 & 146 \\
\hline $\begin{array}{l}\text { CVD-77: As CVD-11 + multidrug } \\
\text { treatment of post-acute IHD \& stroke } \\
\text { + diuretics \& exercise for CHF }\end{array}$ & 4649 & 0.52 & 112 & 129 & 4386 & 0.62 & 142 & 152 \\
\hline $\begin{array}{l}\text { CVD-78: As CVD-11 + multidrug } \\
\text { treatment of acute Ml or post-acute } \\
\text { IHD \& stroke + diuretics \& exercise } \\
\text { for CHF }\end{array}$ & 5265 & 0.62 & 117 & 158 & 5016 & 0.88 & 175 & 404 \\
\hline $\begin{array}{l}\text { CVD-73: Preventive multidrug } \\
\text { treatment for }>25 \% \text { risk of CVD } \\
\text { event + multidrug treatment of acute } \\
\text { Ml or post-acute IHD \& stroke + } \\
\text { diuretics \& exercise for CHF }\end{array}$ & 5431 & 0.81 & 149 & 1165 & 5857 & 1.27 & 216 & 462 \\
\hline $\begin{array}{l}\text { CVD-8: Preventive multidrug } \\
\text { treatment for }>5 \% \text { risk of CVD event }\end{array}$ & 5817 & 2.33 & 401 & 3931 & 7271 & 3.84 & 528 & 1817 \\
\hline \multicolumn{9}{|c|}{ Treatment of diabetes and its complications } \\
\hline $\begin{array}{l}\text { DM-4: Retinopathy screening + } \\
\text { photocoagulation }\end{array}$ & 1228 & 1.00 & 814 & 814 & 1891 & 0.32 & 170 & 170 \\
\hline $\begin{array}{l}\text { DM-6: As DM-4 + standard } \\
\text { glycaemic control }\end{array}$ & 1467 & 2.02 & 1375 & 4266 & 2233 & 1.14 & 512 & 2399 \\
\hline $\begin{array}{l}\text { DM-8: As DM-4 + intensive } \\
\text { glycaemic control }\end{array}$ & 1529 & 3.17 & 2070 & 18419 & 2319 & 2.11 & 912 & 11348 \\
\hline
\end{tabular}

DALYs=disability adjusted life years. \$Int=international dollars.

*\$nt per DALY averted relative to no intervention.

† \$Int per DALY averted, within intervention cluster

$\ddagger$ These interventions are not dominant strategies and results are therefore not included here. 


\section{Figures}
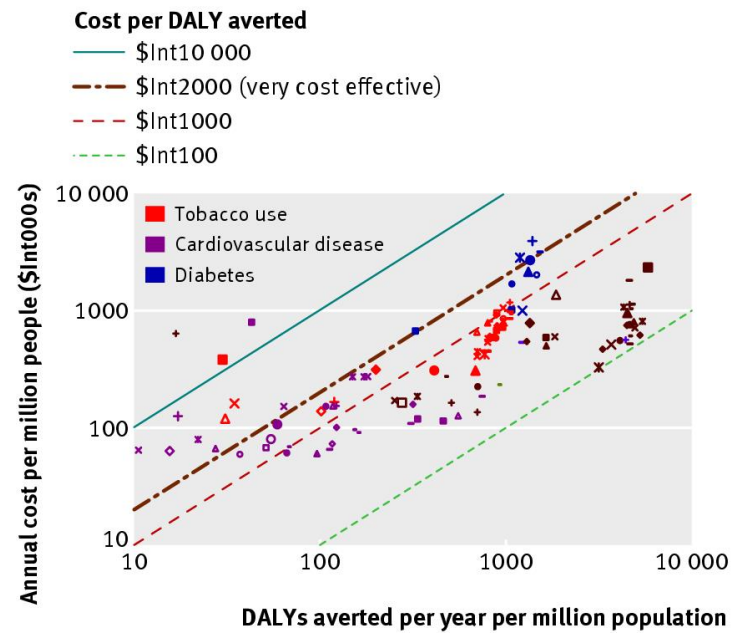

Fig 1 Cost effectiveness of interventions for cardiovascular disease, diabetes, and tobacco use for WHO African sub-region AfrE
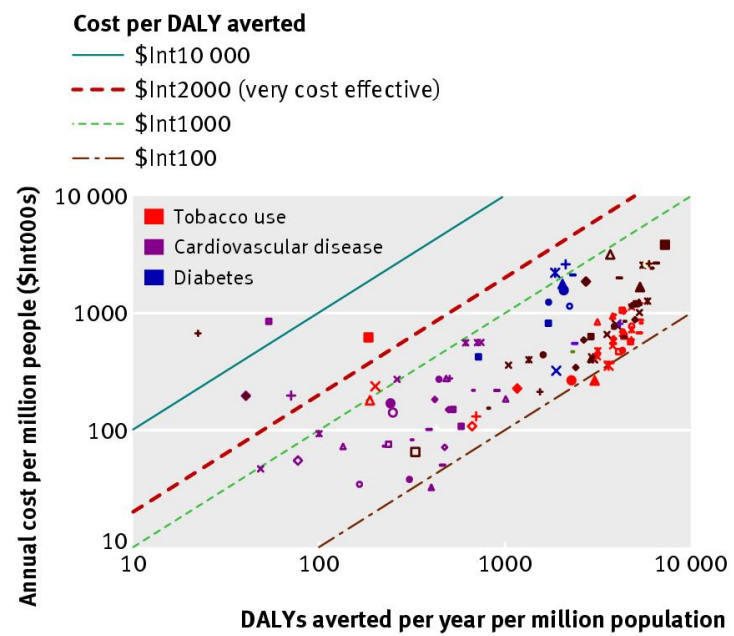

Fig 2 Cost effectiveness of interventions for cardiovascular disease, diabetes, and tobacco use for WHO South-East Asian sub-region SearD 


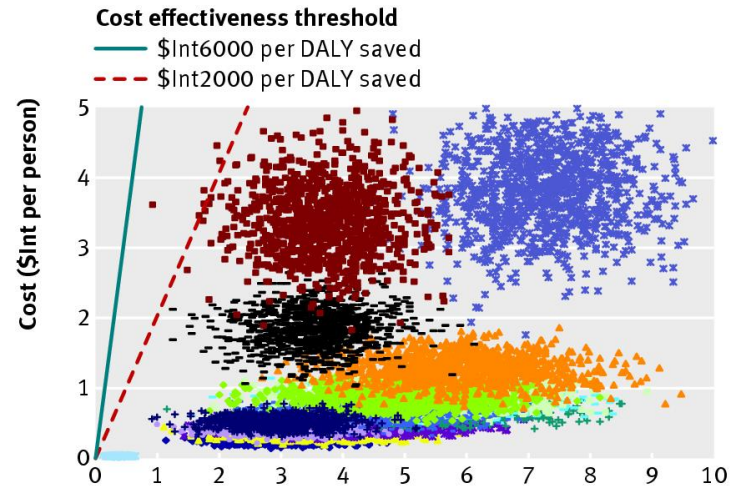

Effect (DALYs (000s) averted per year per million population)

TOB-2 TOB-10 * TOB-15 + TOB-27 - TOB-35 TOB-36

CVD-29 CVD-11 - CVD-77 CVD-78 ACVD-73 *CVD-8

$+\mathrm{DM}-4$ - DM-6 DM-8

Fig 3 Probabilistic uncertainty graph for the less costly and most effective interventions for cardiovascular disease, diabetes, and tobacco use in WHO South East Asia sub-region SearD. See table $4 \Downarrow$ for explanation of intervention codes

Cost effectiveness threshold

$\$$ Int6000 per DALY saved

- - \$Int2000 per DALY saved

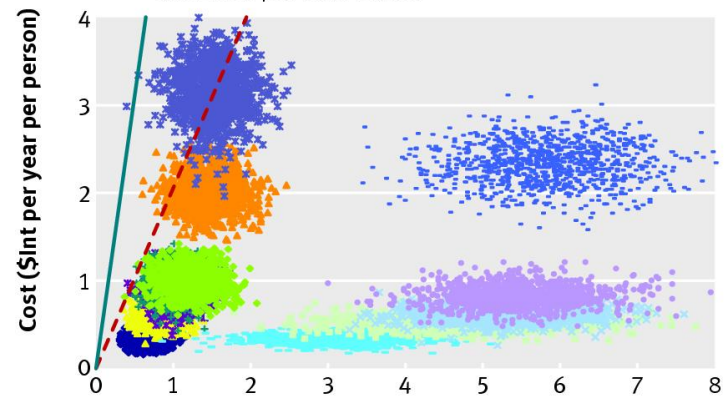

Effect (DALYs (000s) averted per year per million population)

TOB-2 TOB-15 ЖTOB-27 + TOB-36

CVD-11 CVD-77 XVD-78 CVD-73 - CVD-8

DM-4 $\triangle \mathrm{DM}-6$ *DM-8

Fig 4 Probabilistic uncertainty graph for the less costly and most effective interventions for cardiovascular disease, diabetes, and tobacco use in WHO African sub-region AfrE. See table $4 \Downarrow$ for explanation of intervention codes 